http://jmscr.igmpublication.org/home/

ISSN (e)-2347-176x ISSN (p) 2455-0450

crossref DOI: https://dx.doi.org/10.18535/jmscr/v7i11.120

Journal Of Medical Science And Clinical Research

\title{
Association of Quick Sepsis-Related Organ Failure Assessment (qSOFA) to predict Severity in Patients with Pneumonia
}

\author{
Authors \\ Dr Rajeev $\mathbf{H}^{1^{*}}$, Dr Hilas ${ }^{2}$, Dr Tharuni latha ${ }^{3}$, Dr Preethi Gandhi ${ }^{4}$, \\ Dr Anila Jose ${ }^{5}$, Dr Gururaj V Gunda ${ }^{6}$ \\ ${ }^{* 1}$ Professor of Department of General Medicine, KIMS Banglore \\ 2,3,4,5,6 Junior Resident, Department of General Medicine, KIMS Banglore
}

Kempegowda Institute of Medical Sciences and Research Center, Bengaluru, Karnataka, India - 560004

\begin{abstract}
Background: $q S O F A$ is generally useful in predicting the outcome in populations in the general emergency department (ED) in sepsis and most common types of infections to cause sepsis are respiratory like pneumonia or genitourinary like a urinary tract infection. In this study we are evaluating whether qSOFA can predict severity in pneumonia patients during initial assessment.

Aims \& Objectives: To evaluate the association of the qSOFA score to predict admission to the intensive care unit (ICU) and length of hospital stay in patients with pneumonia.

Method: This retrospective study was done at Kempegowda Institute of Medical Sciences and Research Centre, Bengaluru in the Department of Medicine. A total of 50 patients admitted for pneumonia were screened and the qSOFA score was calculated according to initial assessment data, further the admission status and length of stay was also recorded for study.

Results: A total of 50 patients were included in the study out of which 30(60\%) male and 20 (40\%) female patients and the male to female ratio was 1.5:1.Mean age of the participants was 56.60 years. Women subjects were five years younger than males with little variation in dispersion (SD). All the patients had fever and cough with expectoration at the time of presentation. Confusion or disorientation was noticed among $36 \%$ of the patients at presentation. It was observed that with increasing qSOFA score disorientation and pulmonary complications tend to increase. All those who needed ICU care had a score of 2 or more and there was significantly increased duration of hospitalization with qSOFA more than 2 (15 days more in score 3 compared to score 1). qSOFA score predictability in ICU admission showed sensitivity of $100 \%$ and specificity of $35.5 \%$ with positive predictive value of $75 \%$ and negative predictive value of $100 \%$.

Conclusion: qSOFA score showed good predictive performance for ICU admission and in assessing the duration of stay in hospital and hence the severity of pneumonia.
\end{abstract}

\section{Introduction}

Pneumonia is defined as an acute infection of the pulmonary parenchyma, presenting with an acute infiltrate in the chest X-ray ${ }^{[1,2]}$.

Despite on-going advances in medical treatment, the burden of disease of pneumonia remains significant $^{[3]}$. Even in developed countries, the incidence of pneumonia is still as high as 9.7 per 1000 persons, with a hospitalisation rate of $46.5 \%$ and 30-day mortality of $12.9 \%$ in patients with community-acquired pneumonia. ${ }^{[3]}$ 
The case fatality rate increases to over $50 \%$ in patients with pneumonia-related sepsis/septic $\operatorname{shock}^{[3]}$. Therefore, early diagnosis of patients with pneumonia-associated sepsis/septic shock seems paramount.

In 2016, the Society of Critical Care Medicine and the European Society of Intensive Care Medicine concluded that sepsis should be defined as lifethreatening organ dysfunction caused by a dysregulated host response to infection and the Organ dysfunction is represented by an increase in the Sequential [sepsis-related] Organ Failure Assessment (SOFA) score of 2 points or more, which is associated with an in-hospital mortality greater than $10 \%{ }^{[4]}$ The most common types of infections to cause sepsis are respiratory like pneumonia or genitourinary like a urinary tract infection.

However, calculation of SOFA scores requires sequential laboratory work-up and is therefore not useful for bedside screening of patients with suspected sepsis. Therefore, the consensus committee has proposed the quick sequential organ failure score (qSOFA) - which is based on rapidly assessable vital parameters, including respiratory rate, mental status, and systolic blood pressure. $^{[4]}$

The qSOFA model included Glasgow Coma Scale (GCS) score of 13 or less, systolic blood pressure of $100 \mathrm{~mm} \mathrm{Hg}$ or less, and respiratory rate of $22 /$ min or more (1 point each; score range, $0-3$ ). A score $\geq 2$ is associated with poor outcomes due to sepsis. ${ }^{[5]}$

The aim of this study is to evaluate the association of the qSOFA score to predict admission to the intensive care unit (ICU) and length of hospital stay in patients with pneumonia and hence the severity.

\section{Materials \& Methods}

- In a retrospective analysis, admission data in 2018 from Medicine Dept of the KIMS Hospital, were screened to identify 50 patients admitted for pneumonia.
- The following clinical data were recorded; time since start of symptoms, history of fever, history of delirium and risk factors for pneumonia (chronic obstructive pulmonary disease (COPD), diabetes mellitus, liver disease, chronic renal failure, severe cardiac disease, immunosuppression, active neoplasia, smoking, alcoholism).

- In addition, vital parameters were recorded (first recorded value), Glasgow coma scale score was calculated, ABG values, CXR showing multilobar involvement and need for ionotropes, for assessing severity, as well as need for ICU admission. Also the whole duration of hospital stay.

- qSOFA score is calculated from the initial vital parameters assessment.

- Threshold values: qSOFA is considered positive when the patient scored two or more points.

Inclusion Criteria: All adult patients of 16 years or older presenting with the diagnosis of pneumonia were eligible for study.

Exclusion Criteria: Patients with incomplete data sets for the calculation of qSOFA were excluded.

\section{Results}

Patients' Demographics: Of the patients with a diagnosis of pneumonia, 50 with complete datasets to calculate the qSOFA score were identified and were eligible for study inclusion. Of the total patients included,30(60\%) were male and $20(40 \%)$ were female patients and the male to female ratio was 1.5:1.

\section{Gender Distribution}

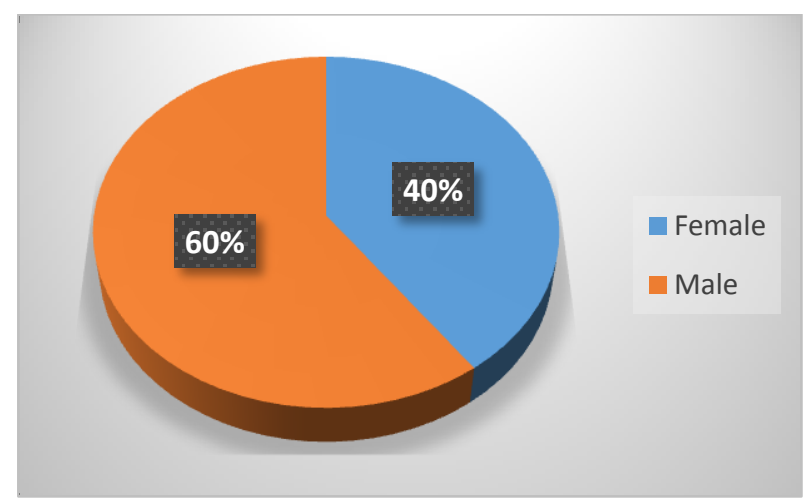




\section{JMSCR Vol||07||Issue||11||Page 688-693||November}

Mean age of the participants was 56.60 years. Women subjects were five years younger than males with little variation in dispersion (SD).

\begin{tabular}{|l|c|c|c|}
\hline $\operatorname{SEX}(0=\mathrm{F}, 1=\mathrm{M})$ & $\mathrm{N}$ & $\begin{array}{c}\text { Mean AGE } \\
\text { IN YEARS }\end{array}$ & $\begin{array}{c}\text { Std. } \\
\text { Deviation }\end{array}$ \\
\hline Female & 20 & 53.20 & 15.109 \\
\hline Male & 30 & 58.87 & 14.998 \\
\hline Total & 50 & 56.60 & 15.150 \\
\hline
\end{tabular}

Frequency distribution of comorbidities among the study subjects, as seen below lifestyle disorders like DM and Hypertension were common comorbidities among the study participants.

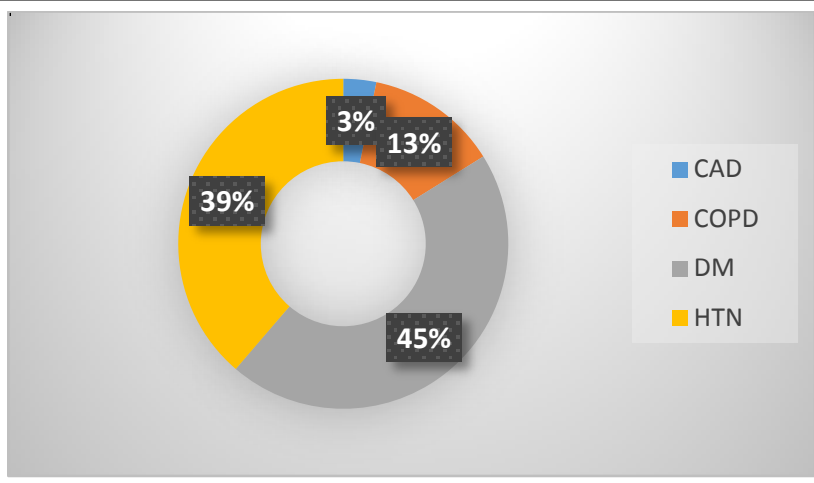

Distribution of presenting symptoms among study subjects: All the patients had fever and cough with expectoration at the time of presentation. Confusion or disorientation was noticed among $36 \%$ of the patients at presentation.

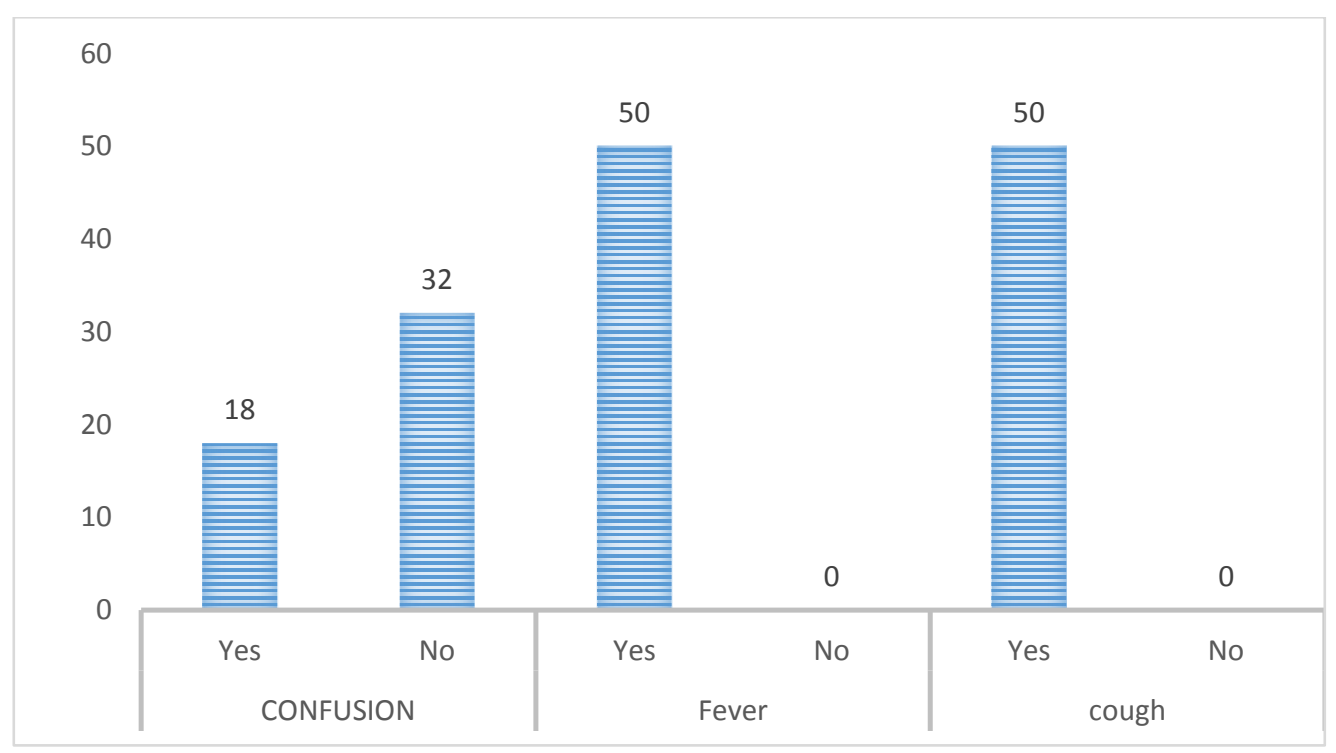

qSOFA Assessment: qSOFA score was positive in 44 patients $(88 \%)$. Patients with a positive qSOFA score did not differ significantly in respect to age, sex, or risk factors for pneumonia from patients with a negative qSOFA score.

\section{Distribution of qSOFA score according to severity of illness}

\begin{tabular}{|c|c|c|c|c|c|c|}
\hline & & \multicolumn{3}{|c|}{ qSOFA Score } & Total & Fisher exact test \\
\hline \multirow{3}{*}{ CONFUSION } & & 1 & 2 & 3 & & $\mathrm{P}$ value \\
\hline & Yes & 0 & 0 & 18 & 18 & $<0.001$ \\
\hline & No & 6 & 26 & 0 & 32 & \\
\hline \multirow[t]{2}{*}{ CHEST XRAY MULTILOBAR } & Yes & 2 & 12 & 12 & 26 & 0.25 \\
\hline & No & 4 & 14 & 6 & 24 & \\
\hline \multirow[t]{2}{*}{ ICU/MICU CARE } & Yes & 0 & 15 & 18 & 33 & $<0.001$ \\
\hline & No & 6 & 11 & 0 & 17 & \\
\hline \multirow[t]{2}{*}{ IONOTROPE } & Yes & 0 & 9 & 8 & 17 & 0.13 \\
\hline & No & 6 & 17 & 10 & 33 & \\
\hline
\end{tabular}

Difference of qSOFA score was studied in different parameters indicating severity of illness.
It was observed that with increasing qSOFA score disorientation and pulmonary complications tend 
to increase. All those who needed ICU care, had score 2 or more. Inotropic support was needed in 17 patients and all of them had score more than or equal to 2 . In all the patients with severe illness symptoms qSOFA score was more than or equal to 2 . The difference was statistically significant for confusion and ICU admission. Similar trend was observed for pulmonary findings and inotrope requirement also. Due to lower sample size the difference observed was not statistically significant.

\section{Distribution of qSOFA score according to clinical parameters of study subjects}

\begin{tabular}{|c|c|c|c|c|c|c|c|c|c|}
\hline qSOFA & & $\begin{array}{l}\text { AGE IN } \\
\text { YEARS }\end{array}$ & $\begin{array}{l}\text { FEVER(No: } \\
\text { of Days) }\end{array}$ & Resp Rate & SPO2 & GCS & $\mathrm{PH}$ & $\mathrm{PO} 2$ & $\begin{array}{c}\text { Days of } \\
\text { Hospitalization }\end{array}$ \\
\hline \multirow[t]{3}{*}{1} & $\mathrm{~N}$ & 6 & 6 & 6 & 6 & 6 & 6 & 6 & 6 \\
\hline & Mean & 57.33 & 5.33 & 22.67 & 93.50 & 15.00 & 7.40 & 83.63 & 5.83 \\
\hline & $\mathrm{SD}$ & 18.875 & 1.751 & 5.007 & 3.886 & 0.000 & 0.05 & 2.68 & .753 \\
\hline \multirow[t]{3}{*}{2} & $\mathrm{~N}$ & 26 & 26 & 26 & 26 & 26 & 26 & 26 & 26 \\
\hline & Mean & 57.27 & 5.50 & 27.38 & 88.00 & 15.00 & 7.39 & 71.19 & 13.46 \\
\hline & SD & 14.842 & 1.631 & 3.806 & 5.824 & 0.000 & 0.08 & 12.16 & 2.687 \\
\hline \multirow[t]{3}{*}{3} & $\mathrm{~N}$ & 18 & 18 & 18 & 18 & 18 & 18 & 18 & 18 \\
\hline & Mean & 55.39 & 5.33 & 31.89 & 81.11 & 13.61 & 7.37 & 60.22 & 20.00 \\
\hline & SD & 15.178 & 1.237 & 5.378 & 12.170 & .502 & 0.09 & 8.99 & 2.249 \\
\hline \multirow[t]{3}{*}{ Total } & $\mathrm{N}$ & 50 & 50 & 50 & 50 & 50 & 50 & 50 & 50 \\
\hline & Mean & 56.60 & 5.42 & 28.44 & 86.18 & 14.50 & 7.39 & 68.73 & 14.90 \\
\hline & SD & 15.150 & 1.486 & 5.388 & 9.380 & .735 & 0.08 & 12.70 & 5.120 \\
\hline \multicolumn{2}{|c|}{ ANOVA test $-\mathrm{F}$ value } & .087 & .076 & 10.632 & 5.942 & 122.078 & .277 & 12.857 & 88.592 \\
\hline \multicolumn{2}{|c|}{ P value } & .917 & .927 & $<0.001$ & 0.005 & $<0.001$ & .759 & $<0.001$ & $<0.001$ \\
\hline
\end{tabular}

No difference was observed in age, duration of pyrexia and $\mathrm{Ph}$ distribution of 3 score categories. Again the investigations like SPO2, GCS and PO2 indicating severe illness showed statistically significant worsening in values with increasing qSOFA score. This was also supported by significantly increased duration of hospitalization (15 days more in score 3 compared to score 1 ).

Distribution of qSOFA categories according to clinical parameters

\begin{tabular}{|c|c|c|c|c|c|c|c|c|c|}
\hline qSOFAcat & & $\begin{array}{l}\text { AGE IN } \\
\text { YEARS }\end{array}$ & $\begin{array}{l}\text { FEVER(No } \\
\text { : of Days) }\end{array}$ & $\begin{array}{l}\text { RESPIRATORY } \\
\text { RATE }\end{array}$ & $\mathrm{SPO} 2$ & GCS & PH & $\mathrm{PO} 2$ & $\begin{array}{c}\text { Days of } \\
\text { Hospitalization }\end{array}$ \\
\hline \multirow[t]{3}{*}{ Negative } & $\mathrm{N}$ & 6 & 6 & 6 & 6 & 6 & 6 & 6 & 6 \\
\hline & Mean & 57.33 & 5.33 & 22.67 & 93.50 & 15.00 & 7.40 & 83.63 & 5.83 \\
\hline & SD & 18.88 & 1.75 & 5.01 & 3.89 & 0.00 & 0.05 & 2.68 & 0.75 \\
\hline \multirow[t]{3}{*}{ Positive } & $\mathrm{N}$ & 44 & 44 & 44 & 44 & 44 & 44 & 44 & 44 \\
\hline & Mean & 56.50 & 5.43 & 29.23 & 85.18 & 14.43 & 7.38 & 66.70 & 16.14 \\
\hline & SD & 14.83 & 1.47 & 4.99 & 9.49 & 0.76 & 0.09 & 12.16 & 4.10 \\
\hline \multicolumn{2}{|c|}{$\mathrm{t}$ test statistic } & 0.02 & 0.02 & 9.13 & 4.44 & 3.30 & 191 & 11.370 & 37.158 \\
\hline \multicolumn{2}{|c|}{$\mathrm{p}$ value } & 0.901 & 0.881 & 0.004 & 0.040 & 0.076 & .664 & .001 & 0.001 \\
\hline
\end{tabular}

Distribution of study subjects according to qSOFA category and severity of illness

$\begin{array}{llc}\text { CONFUSION } & & \text { Ye } \\ \text { CHEST } & \text { XRAY } & \text { Ye } \\ \text { MULTILOBAR } & & \\ & \text { NO } \\ \text { ICU/MICU CARE } & \text { Ye } \\ \text { IONOTROPE } & \text { No } \\ & \text { Ye } \\ & & \text { No }\end{array}$

qSOFA cat

\begin{tabular}{|c|c|c|c|}
\hline \multicolumn{2}{|c|}{ qSOFA cat } & \multirow{2}{*}{$\begin{array}{l}\text { Fischer's exact } \\
\text { test statistic }\end{array}$} & \multirow{2}{*}{$P$ value } \\
\hline Negative & Positive & & \\
\hline 0 & 18 & 3.80 & 0.08 \\
\hline 6 & 26 & & \\
\hline 2 & 24 & 0.95 & 0.41 \\
\hline 4 & 20 & & \\
\hline 0 & 33 & 13.25 & 0.001 \\
\hline 6 & 11 & & \\
\hline 0 & 17 & 3.51 & 0.08 \\
\hline 6 & 27 & & \\
\hline
\end{tabular}




\section{Predictive value of qSOFA score}

qSOFA predictability in ICU admission showed Sensitivity of $100 \%$, Specificity of $35.5 \%$ and a Positive predictive value of $75 \%$ and

For the use inotropes showed sensitivity of $100 \%$, specificity of $18.2 \%$ and Positive predictive value of $38.6 \%$ and negative predictive value of $100 \%$.

\section{Discussion}

qSOFA is generally useful in predicting the outcome prediction abilities in populations in the general emergency department (ED) or intensive care unit (ICU). This score is a modified version of the Sequential (Sepsis-related) Organ Failure Assessment score (SOFA) called the quick SOFA (qSOFA) score. The qSOFA model included Glasgow Coma Scale (GCS) score of 13 or less, systolic blood pressure of $100 \mathrm{~mm} \mathrm{Hg}$ or less, and respiratory rate of $22 / \mathrm{min}$ or more (1 point each; score range, 0-3). A score $\geq 2$ is associated with poor outcomes due to sepsis. Sepsis is defined as life-threatening organ dysfunction caused by a dysregulated host response to infection. The most common types of infections to cause sepsis are respiratory like pneumonia or genitourinary like a urinary tract infection.

This study analysed the predictive performance of qSOFA to assess severity in ED patients with pneumonia in regard to ICU admission and length of hospital stay and the need for ionotropes. And our results show that qSOFA score of more than 1(ie, positive) observed significant worse course of illness among the study subjects. This was supported by high sensitivity and NPV (100\%) in predicting ICU admission and inotropic support requirement.

As qSOFA requires only a clinical examination its predictive capability for assessing severity in condition like pneumonia in hospitals in resourcelimited settings in low-and middle-income countries (LMICs) like India with many primary health centres, which often do not have the laboratory capacity or financial resources to routinely perform a complete blood count test and blood chemistry among all patients with suspected pneumonia will help in identifying critical patients and further can even help in considering transferring a patient to a higher or tertiary healthcare centre.

\section{Limitations of the Study}

First, we included a population admitted to a single center. Second, specificity was lower and the scoring system needs to be tested by large sample studies for further validation.

\section{Conclusions}

qSOFA predicts, length of hospitalisation, and ICU admission in ED patients presenting with pneumonia and has the advantage of being a pure bedside test. As it requires no laboratory testing, it may be more practical in hospitals with less facilities.

\section{Acknowledgement}

We extend our gratitude to all the faculty members of Department of General medicine for giving valuable suggestions for working towards this article.

\section{References}

1. Mandell LA, Wunderink RG, Anzueto A, Bartlett JG, Campbell GD, Dean NC, et al. Infectious Diseases Society of America/American Thoracic Society consensus guidelines on the management of community-acquired pneumonia in adults. Clin Infect Dis. 2007; 44 Suppl 2:S27-72. doi: 10.1086/511159. PMID: 17278083.

2. Corrado RE, Lee D, Lucero DE, Varma JK, Vora NM. Burden of Adult Community-Acquired, HealthcareAssociated, Hospital-Acquired, and Ventilator-Associated Pneumonia-New York City, 2010- 2014. Chest. 2017. doi: 10.1016/j.chest.2017.04.162. PMID: 28455128.

3. Kolditz M, Tesch F, Mocke L, Hoffken G, Ewig S, Schmitt J. Burden and risk factors 
of ambulatory or hospitalized CAP: A population based cohort study. Respir Med. 2016; 121:32-8. doi: 10.1016/j.rmed. 2016.10.015. PMID: 27888989.

4. Seymour CW, Liu VX, Iwashyna TJ, Brunkhorst FM, Rea TD, Scherag A, et al. Assessment of Clinical Criteria for Sepsis: For the Third International Consensus Definitions for Sepsis and Septic Shock (Sepsis-3). JAMA. 2016; 315(8):762-74. doi: 10.1001/jama.2016.0288. PMID: 26903335.

5. Association of the Quick Sequential (Sepsis-Related) Organ Failure Assessment (qSOFA) Score With Excess Hospital Mortality in Adults With Suspected Infection in Low- and MiddleIncome Countries. JAMA. 2018;319 (21):2202. 